\title{
The association between SGLT2 inhibitors and new-onset arrhythmias: a nationwide population-based longitudinal cohort study
}

Hung-Yi Chen ${ }^{1}$, Jing-Yang Huang ${ }^{2}$, Wun-Zhih Siao ${ }^{3+}$ and Gwo-Ping Jong ${ }^{3{ }^{*+}}$

\begin{abstract}
Background: Clinical trials have shown the cardiovascular protective effect of sodium-glucose cotransporter-2 (SGLT2) inhibitors and reduced hospitalization for heart failure. However, no study has investigated the association between SGLT2 inhibitors and the risk of arrhythmias. This study aimed to evaluate the risk of new-onset arrhythmias (NOA) and all-cause mortality with the use of SGLT2 inhibitors.

Methods: This was a population-based cohort study utilizing Taiwan's National Health Insurance Research Database. Each patient aged 20 years and older who took SGLT2 inhibitors was assigned to the SGLT2 inhibitor group, whereas sex-, age-, diabetes mellitus duration-, drug index date-, and propensity score-matched randomly selected patients without SGLT2 inhibitors were assigned to the non-SGLT2 inhibitor group. The study outcome was all-cause mortality and NOA.
\end{abstract}

Results: A total of 399,810 patients newly diagnosed with type 2 DM were enrolled. A 1:1 matching propensity method was used to match 79,150 patients to 79,150 controls in the non-SGLT2 inhibitors group for analysis. The SGLT2 inhibitor group was associated with a lower risk of all-cause mortality [adjusted hazard ratio (aHR) 0.547; 95\% confidence interval (Cl) $0.482-0.621 ; P=0.0001$ ] and NOA (aHR 0.830; 95\% $\mathrm{Cl} 0.751-0.916 ; P=0.0002$ ).

Conclusions: Patients with type 2 DM prescribed with SGLT2 inhibitors were associated with a lower risk of all-cause mortality and NOA compared with those not taking SGLT2 inhibitors in real-world practice.

Keywords: Sodium-glucose co-transporter inhibitors, Diabetes mellitus, Arrhythmias

\section{Background}

The global incidence and prevalence of diabetes mellitus (DM) increased over the past two decades and caused much health burden worldwide $[1,2]$. DM is associated with an increased risk of atherosclerotic cardiovascular diseases such as coronary artery disease, myocardial infarction, and peripheral artery occlusive

\footnotetext{
*Correspondence: cgp8009@yahoo.com.tw

tWun-Zhih Siao and Gwo-Ping Jong contributed equally to this work ${ }^{3}$ Division of Cardiology, Department of Internal Medicine, Chung Shan Medical University Hospital and Chung Shan Medical University, Taichung, Taiwan, ROC

Full list of author information is available at the end of the article
}

disease. Otherwise, patients with DM are prone to develop arrhythmias, which contributed to autonomic, electrical, and structural remodeling, as well as insulin resistance and glycemic fluctuations [3, 4]. DM is also a strong risk factor for sudden cardiac death and responsible for arrhythmic deaths [5, 6]. Once a diabetic population develops arrhythmias, they have a worse prognosis [7]. Sodium-glucose cotransporter-2 (SGLT2) inhibitors as antihyperglycemic drugs are proven to have a cardiovascular protective effect in reducing cardiovascular death and hospitalization for heart failure (hHF) in large randomized trials [8-10]. Animal studies and clinical trials have shown a sympathoinhibitory effect by SGLT2 inhibitors, which play an important role in

c) The Author(s) 2020. This article is licensed under a Creative Commons Attribution 4.0 International License, which permits use, sharing, adaptation, distribution and reproduction in any medium or format, as long as you give appropriate credit to the original author(s) and the source, provide a link to the Creative Commons licence, and indicate if changes were made. The images or other third party material in this article are included in the article's Creative Commons licence, unless indicated otherwise in a credit line to the material. If material is not included in the article's Creative Commons licence and your intended use is not permitted by statutory regulation or exceeds the permitted use, you will need to obtain permission directly from the copyright holder. To view a copy of this licence, visit http://creativeco mmons.org/licenses/by/4.0/. The Creative Commons Public Domain Dedication waiver (http://creativecommons.org/publicdomain/ zero/1.0/) applies to the data made available in this article, unless otherwise stated in a credit line to the data. 
arrhythmogenesis [11-14]. SGLT2 inhibitors also reduce cardiac fibrosis and left ventricular hypertrophy, which serves as a substrate for arrhythmia development [15, 16]. However, no study has investigated the association of risk of arrhythmias and the use of SGLT2 inhibitors in diabetes populations until now in real-world practice. The purpose of the present study was to evaluate the risk of arrhythmias and all-cause mortality associated with prescription of SGLT2 inhibitors in a nationwide cohort study of diabetic patients in Taiwan.

\section{Methods}

\section{Data source}

This study was approved by the Institutional Review Board of Chung Shan Medical University Hospital, Taiwan. This study extracted data from the National Health Insurance (NHI) program, which is a compulsory universal health insurance program in Taiwan. The NHI database provides comprehensive medical care coverage to more than $99 \%$ of Taiwanese residents. It stores information including claim forms and contains patient identification such as numbers, sex, age, three diagnostic codes, medical expenditures, hospital, physician information, and prescriptions such as the drug quantity and expenditure, drug dose, operations, and treatments. Informed consent was waived owing to the retrospective nature of the study; each patient in the NHI research database was encrypted and de-identified to protect their privacy.

\section{Study cohort and outcomes}

This case-control study extracted data from the NHI program in Taiwan from January 2004 to December 2017 using newly diagnosed type 2 DM codes based on the International Classification of Diseases, ninth revision, Clinical Modification (ICD-9-CM) and ICD, tenth revision, CM (ICD-10-CM). The newly diagnosed type 2 DM was defined as the first time that a type 2 DM code was available in the outpatient or inpatient claim records between January 2004 and December 2017. The list of ICD-9 and ICD-10 codes that used to defined the inclusion of T2DM patients, study events, and co-morbidities were presented in Additional file 1: Table S1.

A flowchart for the enrollment of the study cohort is summarized in Fig. 1. Study subjects were divided into two groups: those taking SGLT2 inhibitors (the SGLT2 inhibitors group, $n=95,174)$ and those not taking SGLT2 inhibitors (the non-SGLT2 inhibitor group, $n=2,025,207)$. Among the SGLT2 inhibitor group, 9542 patients were excluded because of a diagnosis of any arrhythmias $(n=7744)$ before the index date, use of SGLT2 inhibitor for less than 1 month $(n=1794)$, and death $(n=4)$. A total of 79,150 patients were selected for this study.
Both the SGLT2 inhibitor and non-SGLT2 inhibitor groups were stratified in a 1:1 ratio. The study group comprised 79,150 participants with SGLT2 inhibitors as antihyperglycemic drugs, and the control group included 79,150 age-, sex-, DM duration-, drug index date-, and propensity score-matched randomly selected participants without SGLT2 inhibitors.

The first claim date of the SGLT2 inhibitors was defined as the drug index date in the SGLT2 inhibitor group, with the same day of the matched non-SGLT2 inhibitor group. Two types of SGLT2 inhibitors (empagliflozin and dapagliflozin) were launched on May 1, 2016 and their till to end of study (Dec. 31, 2017). Median (Q1-Q3, Maximum) of follow up time was $9(4-14,21)$, in SGLT2 inhibitors group was $9(5,14)$, in non-SGLT2 inhibitors group was $9(4,14)$. In NHIRD, the records of prescriptions were uploaded when the medications were filled. We followed the SGLT2 inhibitors users since their first prescription of SGLT2 inhibitors, until the occurrence of study event or end of study. The intention to treat analysis was performed in this study, we analyzed according to the group they were originally assigned, regardless of their adherence or duration on usage of SGLT2 inhibitor. The study outcome was defined by the all-cause mortality and new-onset arrhythmias (NOA), including atrial fibrillation, atrial flutter, atrial premature complexes, paroxysmal supraventricular tachycardia, ventricular tachycardia, ventricular fibrillation, and ventricular premature complexes, based on the ICD-9-CM and ICD-10-CM codes, in either an outpatient or inpatient department at least once from May 1, 2016 to December 31, 2017.

\section{Statistical analysis}

Data are presented as valid percentages and mean values with a standard deviation. The standardized difference was applied to determine the difference in baseline characteristics between the two study groups. The propensity score method was used to compare the effect between the two study groups on study outcomes. Inverse probability of treatment weighting of propensity scores was used to balance covariates across the two study groups [17]. The balance of potential confounders at baseline (index date) between the two study groups was evaluated using absolute standardized difference, rather than statistical testing, because balance is a property of the sample and not of an underlying population. A value of the absolute standardized difference $\leq 0.1$ suggested a negligible difference in potential confounders between the two study groups (Table 1). The Cox proportional hazard regression model was used to compare the risk of developing study events between the SGLT2 inhibitor group and the non-SGLT2 inhibitor group. Adjusted hazard ratios (HRs) and 95\% 


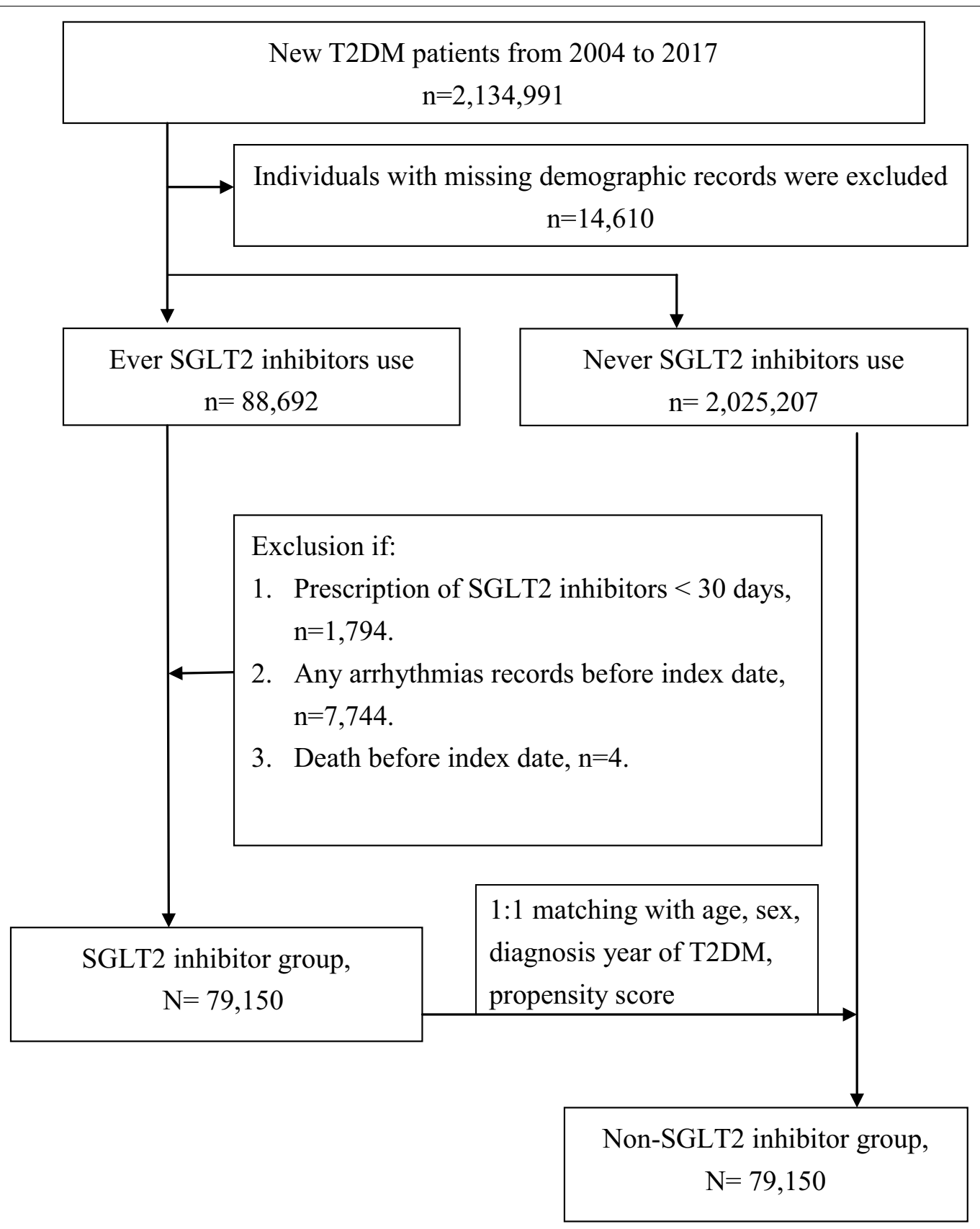

Fig. 1 Flowchart of study population

confidence intervals (CIs) were calculated, adjusting for important risk factors for developing study events, including age, sex, medication use, and comorbidities. The risk of study outcomes overtime for the SGLT2 inhibitor group compared with the non-SGLT2 inhibitor group was determined using survival analysis with the Kaplan-Meier method. Finally, the Cox regression model was used as a sensitivity analysis by age $\geq 60$ or
$<60$ years. All effects were analyzed using an intentionto-treat approach. Statistical significance was defined at a P-value of $<0.05$.

\section{Results}

In total, 79,150 pairs were included after age, sex, DM duration, drug index date, and propensity score matching. The baseline characteristics of all patients between 
Table 1 Baseline characteristics among study cohorts before and after propensity score matching

\begin{tabular}{|c|c|c|c|c|c|c|}
\hline & Before PSM & & & After PSM & & \\
\hline & Non-SGLT2i & SGLT2i & ASD & Non-SGLT2i & SGLT2i & ASD \\
\hline & $\mathrm{N}=319,848$ & $N=79,962$ & & $N=79,150$ & $N=79,150$ & \\
\hline Year of T2DM diagnosis & & & 0.000 & & & 0.082 \\
\hline 2004 & $29,528(9.23 \%)$ & $7382(9.23 \%)$ & & 7643 (9.66\%) & 7311 (9.24\%) & \\
\hline 2005 & $25,620(8.01 \%)$ & $6405(8.01 \%)$ & & 6515 (8.23\%) & 6347 (8.02\%) & \\
\hline 2006 & 25,508 (7.98\%) & $6377(7.98 \%)$ & & $6586(8.32 \%)$ & 6322 (7.99\%) & \\
\hline 2007 & $26,372(8.25 \%)$ & $6593(8.25 \%)$ & & $6646(8.4 \%)$ & 6518 (8.23\%) & \\
\hline 2008 & $26,040(8.14 \%)$ & $6510(8.14 \%)$ & & 6594 (8.33\%) & $6454(8.15 \%)$ & \\
\hline 2009 & $26,920(8.42 \%)$ & $6730(8.42 \%)$ & & $6653(8.41 \%)$ & 6664 (8.42\%) & \\
\hline 2010 & $24,684(7.72 \%)$ & $6171(7.72 \%)$ & & $5948(7.51 \%)$ & 6102 (7.71\%) & \\
\hline 2011 & 23,324 (7.29\%) & $5831(7.29 \%)$ & & 5577 (7.05\%) & 5761 (7.28\%) & \\
\hline 2012 & $22,500(7.03 \%)$ & $5625(7.03 \%)$ & & $5312(6.71 \%)$ & $5562(7.03 \%)$ & \\
\hline 2013 & $21,528(6.73 \%)$ & $5382(6.73 \%)$ & & $5123(6.47 \%)$ & 5317 (6.72\%) & \\
\hline 2014 & $19,976(6.25 \%)$ & 4994 (6.25\%) & & $4574(5.78 \%)$ & 4941 (6.24\%) & \\
\hline 2015 & $18,872(5.90 \%)$ & $4718(5.90 \%)$ & & 4491 (5.67\%) & 4661 (5.89\%) & \\
\hline 2016 & 17,108 (5.35\%) & $4277(5.35 \%)$ & & 4356 (5.50\%) & 4244 (5.36\%) & \\
\hline 2017 & 11,868 (3.71\%) & $2967(3.71 \%)$ & & 3132 (3.96\%) & 2946 (3.72\%) & \\
\hline Sex & & & 0.000 & & & 0.014 \\
\hline Male & $179,252(56.04 \%)$ & $44,813(56.04 \%)$ & & $44,751(56.54 \%)$ & 44,360 (56.05\%) & \\
\hline Female & $140,596(43.96 \%)$ & $35,149(43.96 \%)$ & & $34,399(43.46 \%)$ & 34,790 (43.95\%) & \\
\hline Age & & & 0.000 & & & 0.039 \\
\hline$<50$ & 99,056 (30.97\%) & 24,764 (30.97\%) & & $24,179(30.55 \%)$ & 24,471 (30.92\%) & \\
\hline $50-60$ & $105,012(32.83 \%)$ & $26,253(32.83 \%)$ & & $26,379(33.33 \%)$ & 26,037 (32.90\%) & \\
\hline $60-70$ & 87,708 (27.42\%) & $21,927(27.42 \%)$ & & $21,897(27.67 \%)$ & 21,705 (27.42\%) & \\
\hline$\geq 70$ & 28,072 (8.78\%) & $7018(8.78 \%)$ & & $6695(8.46 \%)$ & 6937 (8.76\%) & \\
\hline Comorbidities & & & & & & \\
\hline Hypertension & $155,971(48.76 \%)$ & $47,428(59.31 \%)$ & 0.213 & $47,636(60.18 \%)$ & $46,839(59.18 \%)$ & 0.021 \\
\hline Hyperlipidemia & $163,107(51.00 \%)$ & $55,788(69.77 \%)$ & 0.391 & $57,253(72.33 \%)$ & 55,107 (69.62\%) & 0.060 \\
\hline Cirrhosis & $7638(2.39 \%)$ & $2152(2.69 \%)$ & 0.019 & 2070 (2.62\%) & 2117 (2.67\%) & 0.004 \\
\hline COPD & $8870(2.77 \%)$ & 2009 (2.51\%) & 0.016 & $1932(2.44 \%)$ & $1983(2.51 \%)$ & 0.004 \\
\hline Sleep apnea & $1516(0.47 \%)$ & $584(0.73 \%)$ & 0.033 & $512(0.65 \%)$ & $561(0.71 \%)$ & 0.008 \\
\hline Concurrent medication & & & & & & \\
\hline NSIADs (exclude aspirin) & $68,643(21.46 \%)$ & $16,491(20.62 \%)$ & 0.021 & $16,423(20.75 \%)$ & $16,349(20.66 \%)$ & 0.002 \\
\hline Systemic corticosteroids & $17,933(5.61 \%)$ & $4258(5.33 \%)$ & 0.012 & 4192 (5.3\%) & 4203 (5.31\%) & 0.001 \\
\hline PPIs & $20,853(6.52 \%)$ & $5043(6.31 \%)$ & 0.009 & $4860(6.14 \%)$ & $4984(6.3 \%)$ & 0.006 \\
\hline $\mathrm{H} 2$ receptor inhibitors & 37,135 (11.61\%) & $9502(11.88 \%)$ & 0.008 & $9262(11.7 \%)$ & $9391(11.86 \%)$ & 0.005 \\
\hline Aspirins & $49,502(15.48 \%)$ & $18,635(23.30 \%)$ & 0.199 & $17,980(22.72 \%)$ & 18,278 (23.09\%) & 0.009 \\
\hline Biguanides & 141,971 (44.39\%) & $54,094(67.65 \%)$ & 0.482 & $55,453(70.06 \%)$ & $53,339(67.39 \%)$ & 0.058 \\
\hline Sulfonylureas & $95,541(29.87 \%)$ & $37,970(47.49 \%)$ & 0.368 & $38,563(48.72 \%)$ & $37,359(47.2 \%)$ & 0.030 \\
\hline Alpha glucosidase inhibitors & $27,832(8.7 \%)$ & $16,654(20.83 \%)$ & 0.347 & $15,144(19.13 \%)$ & $16,149(20.4 \%)$ & 0.032 \\
\hline Thiazolidinediones & $26,241(8.2 \%)$ & $14,809(18.52 \%)$ & 0.307 & $13,905(17.57 \%)$ & $14,393(18.18 \%)$ & 0.016 \\
\hline DPP4is & $54,820(17.14 \%)$ & $34,119(42.67 \%)$ & 0.581 & $32,709(41.33 \%)$ & $33,358(42.15 \%)$ & 0.017 \\
\hline Insulin & $23,666(7.40 \%)$ & $14,210(17.77 \%)$ & 0.317 & $13,001(16.43 \%)$ & $13,716(17.33 \%)$ & 0.024 \\
\hline Alpha-blockers & $9202(2.88 \%)$ & 2590 (3.24\%) & 0.021 & $2522(3.19 \%)$ & 2564 (3.24\%) & 0.003 \\
\hline Beta-blockers & 64,898 (20.29\%) & $21,416(26.78 \%)$ & 0.153 & $20,747(26.21 \%)$ & 21,057 (26.6\%) & 0.009 \\
\hline CCBs & $76,458(23.90 \%)$ & $19,026(23.79 \%)$ & 0.003 & $19,097(24.13 \%)$ & $18,848(23.81 \%)$ & 0.007 \\
\hline ACEIs & $17,276(5.40 \%)$ & 5415 (6.77\%) & 0.057 & $5403(6.83 \%)$ & $5349(6.76 \%)$ & 0.003 \\
\hline ARBs & $119,902(37.49 \%)$ & $42,612(53.29 \%)$ & 0.321 & $42,504(53.7 \%)$ & $41,975(53.03 \%)$ & 0.013 \\
\hline Statins & 148,755 (46.51\%) & $57,867(72.37 \%)$ & 0.546 & 58,549 (73.97\%) & 57,092 (72.13\%) & 0.042 \\
\hline
\end{tabular}


Table 1 (continued)

The comorbidities were defined by disease diagnosis (ICD-9 or ICD-10) that listed in Additional file 1: Table S1

PSM propensity score matching, SGLT2i Sodium-glucose cotransporter 2 inhibitors, ASD absolute standardized difference, COPD chronic obstructive pulmonary disease, $P V D$ peripheral vascular disease, $P C I$ percutaneous coronary intervention, NSIAD non-steroidal anti-inflammatory drug, $P P I$ proton pump inhibitor, $D P P-4 i$ dipeptidyl peptidase 4 inhibitor, $C C B$ calcium channel blocker, $A C E l$ angiotension-converting enzyme inhibitor, $A R B$ angiotensin receptor blocker

Table 2 Incidence of study events in population between SGLT2 inhibitor group and non- SGLT2 inhibitor group

\begin{tabular}{|c|c|c|c|c|c|c|}
\hline & \multicolumn{2}{|c|}{ Non-SGLT2i } & \multicolumn{2}{|l|}{ SGLT2i } & \multirow[t]{2}{*}{ cHR } & \multirow[t]{2}{*}{ aHR } \\
\hline & $\mathrm{Pm}$ & Events & $\mathrm{Pm}$ & Events & & \\
\hline All-cause death & 733,896 & 666 & 742,390 & 380 & $0.564(0.497-0.640)$ & $0.547(0.482-0.621)$ \\
\hline NOA & 728,545 & 858 & 737,979 & 721 & $0.832(0.754-0.919)$ & $0.830(0.751-0.916)$ \\
\hline Atrial fibrillation & 733,017 & 146 & 741,713 & 125 & $0.849(0.668-1.077)$ & $0.841(0.662-1.068)$ \\
\hline Supraventricular arrhythmias & 733,479 & 67 & 742,054 & 54 & $0.799(0.558-1.143)$ & $0.815(0.570-1.167)$ \\
\hline Ventricular arrhythmias & 733,651 & 50 & 742,207 & 41 & $0.813(0.538-1.229)$ & $0.797(0.525-1.208)$ \\
\hline
\end{tabular}

aHR, controlled for age, sex, comorbidities, and concurrent medications

Supraventricular arrhythmias include atrial premature complexes and paroxysmal supraventricular tachycardia; ventricular arrhythmias include ventricular tachycardia, ventricular fibrillation and ventricular premature complexes

SGLT2i sodium-glucose co-transporter 2 inhibitor, Pm Person-months, CHR crude hazard ratio, aHR adjusted hazard ratio, NOA new-onset arrhythmias

the SGLT2 inhibitor group and the non-SGLT2 inhibitor group are presented in Table 1 . The absolute standardized differences between the two groups in all variables were $<0.1(10 \%)$, and the differences between matched pairs were statistically negligible.

In total, 1046 all-cause death events were observed among the matched patients during the follow-up period. The SGLT2 inhibitor group was associated with a lower risk of all-cause mortality [adjusted hazard ratio (aHR): 0.547; 95\% confidential interval (CI) $0.482-0.621 ; P=0.0001]$. Total events of NOA were 1579 , including atrial fibrillation $(n=271)$, supraventricular arrhythmias $(n=121)$, and ventricular arrhythmias $(n=91)$. The aHRs of NOA were 0.830 (95\% CI $0.751-0.916 ; P=0.002)$ in the SGLT2 inhibitor group. The events and incidence rate of all-cause death and NOA are shown in Table 2. There is a clear separation of event curves for all-cause mortality and NOA between these two groups, as shown in Figs. 2 and 3 .

We performed several sensitivity analyses to investigate the effect of SGLT2 inhibitor on all-cause death and NOA. Exclusion of all NOA events for participants of an all-cause death event within 60 years old provided similar results (147 vs. 238 events, HR 0.47, 95\% CI 0.35 to 0.63 ; Table 3$)$. Similar findings were seen when participants aged $\geq 60$ years did not experience NOA at any time during the study (233 vs. 361 events; HR 0.57, 95\% CI 0.45 to 0.72 ; Table 3). Similarly, a consistent treatment effect of NOA was seen when participants age within 60 years did not experience an all-cause death event (369 vs. 452 events; HR 0.81, 95\% CI 0.67

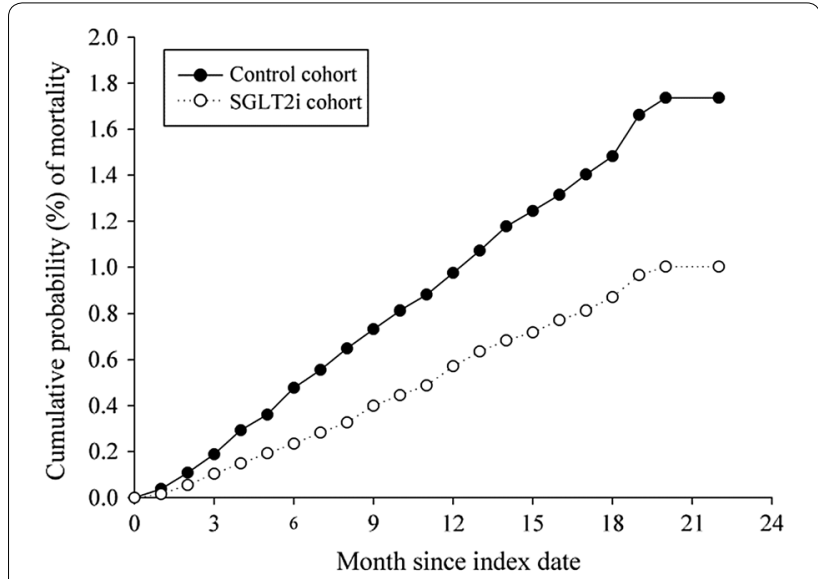

Fig. 2 Cumulative risk curve of all-cause mortality for the study cohorts treated with SGLT2 inhibitors vs. non-SGLT2 inhibitors user

to 0.99 ) or at any time during the study (352 vs. 406 events; HR 0.83, 95\% CI 0.68 to 1.01 ; Table 3 ).

\section{Discussion}

In this population-based cohort study, we observed that patients taking SGLT2 inhibitors had a significantly lower risk of all-cause mortality compared with non-SGLT2 inhibitor users. The risk of NOA among the diabetes population taking SGLT2 inhibitors was decreased by $17 \%$ compared with non-SGLT2 inhibitor users. 


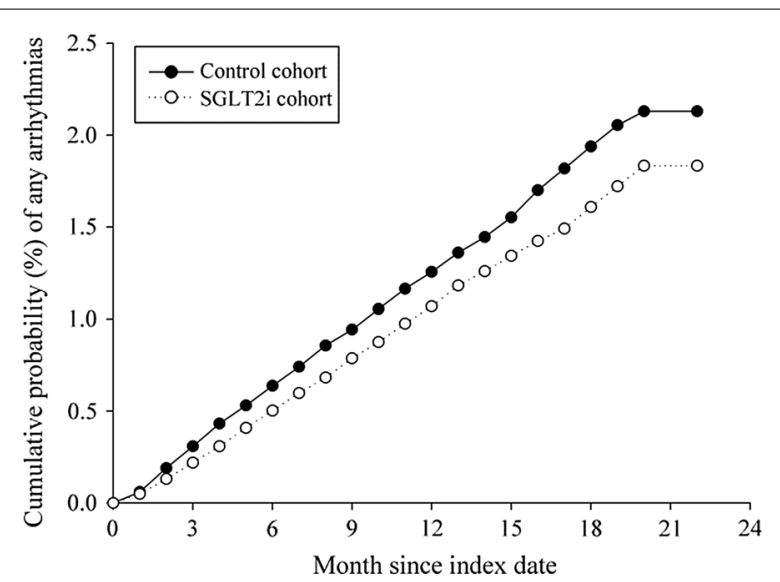

Fig. 3 Cumulative risk curve of new-onset any arrhythmias for the study cohorts treated with SGLT2 inhibitors vs. non-SGLT2 inhibitors users and a first worsening heart failure event [21, 22]. In our study, SGLT2 inhibitor users reduced all-cause mortality by $46 \%$ compared with non-SGLT 2 inhibitor users, which is consistent with the large randomized control trial and observational study [8, 23, 24]. In real-world practice, the multinational CVD-REAL study has shown the lower rate of hHF and death with SGLT2 inhibitor treatment compared with other antihyperglycemic drugs [23]. Simultaneously, a nationwide retrospective observational study that estimated the effect of SGLT2 inhibitors on hHF among diabetes patients suggests that SGLT2 inhibitors reduced hHF compared with dipeptidyl peptidase- 4 inhibitors. The benefit of reduced hHF was noted as earlier as 30 days after initiating the SGLT2 inhibitors among patients with established cardiovascular diseases [25]. The lower risk of hHF occurred during the early phase of the SGLT2 inhibitor initiation, suggesting that patients with heart failure are predisposed to develop

Table 3 Sensitivity analyses

\begin{tabular}{|c|c|c|c|c|c|c|c|c|}
\hline \multirow[t]{2}{*}{ Outcome } & \multicolumn{3}{|l|}{ Non-SGLT2i } & \multicolumn{3}{|l|}{ SGLT2i } & \multirow{2}{*}{$\begin{array}{l}\text { Hazard Ratio } \\
(95 \% \mathrm{Cl})\end{array}$} & \multirow[t]{2}{*}{$P$ value } \\
\hline & $\%$ & 20 M KM (\%) & $\begin{array}{l}\text { Events/10,000 } \\
\text { Ptms }\end{array}$ & $\%$ & 20 KM (\%) & $\begin{array}{l}\text { Events/10,000 } \\
\text { Ptms }\end{array}$ & & \\
\hline $\begin{array}{l}\text { Age }<60 \text { year and } \\
\text { All-cause death }\end{array}$ & d $305(0.60 \%)$ & 0.60 & 6.42 & 147 (0.29\%) & 0.29 & 3.05 & $0.47(0.35-0.63)$ & $<0.001$ \\
\hline $\begin{array}{l}\text { Age } \geq 60 \text { year } \\
\text { and All-cause } \\
\text { death }\end{array}$ & $361(1.26 \%)$ & 1.26 & 13.94 & $233(0.81 \%)$ & 0.81 & 8.93 & $0.57(0.45-0.72)$ & $<0.001$ \\
\hline $\begin{array}{l}\text { Age }<60 \text { year and } \\
\text { NOA }\end{array}$ & d $452(0.89 \%)$ & 0.87 & 9.58 & $369(0.73 \%)$ & 0.72 & 7.70 & $0.81(0.67-0.99)$ & 0.042 \\
\hline $\begin{array}{l}\text { Age } \geq 60 \text { year } \\
\text { and } \mathrm{NOA}\end{array}$ & 406 (1.42\%) & 1.40 & 15.82 & $352(1.23 \%)$ & 1.21 & 13.60 & $0.83(0.68-1.01)$ & 0.061 \\
\hline
\end{tabular}

NOA new-onset arrhythmias, 10,000 Ptms per 10,000 patient months, SGLT2i sodium-glucose cotransporter 2 inhibitors

\section{Cardiovascular protective benefit}

SGLT2, which is significantly increased in patients with type $2 \mathrm{DM}$, is located at the S1 and S2 segments of the proximal tubule epithelium and responsible for around $90 \%$ of filtered glucose reabsorption in the kidney. SGLT2 inhibitors inhibit the reabsorption of filtered glucose, thus increasing glycosuria and also natriuresis [18-20]. The EMPA-REG OUTCOME study and CANVAS program have shown the cardiovascular protection benefit of lowering the risk of cardiovascular death or hHF in type 2 diabetic patients with high risk or established cardiovascular diseases $[8,9]$. Furthermore, the Dapagliflozin on the Incidence of Cardiovascular Events (DECLARE) and Dapagliflozin And Prevention of Adverse-outcomes in Heart Failure (DAPA-HF) trials demonstrated the cardiovascular protective benefit of lowering the risk of cardiovascular death or hHF in patients with type 2 DM with a lower rate of major adverse cardiac events (MACE), arrhythmias. Otherwise, arrhythmias can exacerbate the heart failure symptoms and increase the risk of hHF by decreasing the effective cardiac output $[26,27]$.

\section{Protective effect of arrhythmia}

In the present cohort study, we observed that patients taking SGLT2 inhibitors had a potential protective effect of NOA. Till now, little data are available regarding therapeutic strategies to improve prognosis in these patients. The recent EMPA-REG OUTCOME study showed that administration of the SGLT2 inhibitor, empagliflozin, significantly suppressed cardiovascular death, including sudden cardiac death [8]. This study reported pleiotropic effects, including hypotension and bodyweight reduction, as a result of SGLT2 inhibitor administration. The physiological mechanisms involved in SGLT2 inhibitor administration and cardiac arrhythmia, however, remain unknown. Currently, an observational study by Zelniker 
et al. reported that the risk of atrial fibrillation or atrial flutter was as low as $19 \%$ in patients using empagliflozin [28]. They suggested a possible antiarrhythmic effect of SGLT2 inhibitors, including structural, electromechanical, and mechanical myocardial remodeling and an imbalance in the sympathetic-parasympathetic tone.

To our knowledge, our study is the first real-world data to describe the risk of arrhythmias in DM patients taking SGLT2 inhibitors. Our study suggests that patients with diabetes taking SGLT2 inhibitors can reduce the $17 \%$ risk of arrhythmias development compared with nonSGLT2 inhibitor users, which may be the possible cause of decreasing the risk of hHF observed in current trials.

\section{Strengthens and limitations}

The strengthens of our study included a population-based nature, large sample size, and de-identified data. Our study also has are several limitations. First, the shortest follow-up period in our participants is 20 months. However, the results of all-cause mortality and arrhythmias still showed statistical significance. Second, the laboratory data such as hemoglobin A1c levels, blood sugar levels, renal function, liver function, and electrocardiogram data were not available from these secondary data. This is an important limitation. However, because the data we used were population-based data, we assumed that there were no differences among the two groups. Further randomized clinical trial is needed to confirm our result. Third, we ascertained that the exposure to SGLT2 inhibitors in the cohort is real and supported by the claims data, which include medication prescription. However, treatment adherence was not available from these secondary data. Fourth, the present study was based on a retrospective review of prescription records, which quite naturally were not adequate source of information for specifically looking at cardiac arrhythmias. Hence, it is quite likely that cardiac arrhythmias were underreported at the time of inclusion. However, our results are consistent with those of previous validation studies [29-32]. Fifth, we could not exclude the possibility of time lag bias in this analysis. However, the index date in the control group is the same calendar day as that of the matched SGLT2 inhibitor group. It has about the same amount of time into follow-up after the type 2 DM diagnosis. Therefore, we assumed that there is a low possibility of time lag bias in this analysis.

\section{Conclusion}

Patients with type 2 DM taking SGLT2 inhibitors as antihyperglycemic drugs are associated with a lower risk of all-cause mortality and arrhythmias compared with those without SGLT2 inhibitors prescription in real-world practice.

\section{Supplementary information}

Supplementary information accompanies this paper at https://doi. org/10.1186/s12933-020-01048-x.

Additional file 1: Table S1. The lists of ICD-9 and ICD-10 codes in inclusion criteria, study events, and co-morbidities. Table S2. Subgroup analyses for sex. Table S3. Subgroup analyses for age. Table S4. Subgroup analyses for DM duration. Table S5. Subgroup analyses for comorbidity. Table S6. Subgroup analyses for current medication.

\section{Abbreviations \\ SGLT: Sodium-glucose co-transporter; hHF: Hospitalization for heart failure; T2DM: Type 2 diabetes mellitus; ICD-9-CM: International Classification of Diseases, ninth revision; Clinical Modification; ICD-10-CM: International Clas- sification of Diseases, tenth revision, Clinical Modification Clinical Modification; AF: Atrial fibrillation; RAS: Renin-angiotensin system.}

\section{Acknowledgements}

None.

\section{Authors' contributions}

WZS designed the data and drafted the paper; JYH collected and analyzed the data; HYC and GPJ designed the data, gave critical suggestion, and final approval of the manuscript. All authors read and approved the final manuscript

\section{Funding}

The study was supported by the grant from Chung Shan Medical University Hospital (CSMUH-2019-001) and we thank China Medical University for their financial support.

\section{Availability of data and materials}

All the re-identified data are available upon reasonable request (cgp8009@ yahoo.com.tw).

\section{Ethics approval and consent to participate}

This study was approved by ethics committee of China Medical University Hospital (DMR101-IRB2-194). Written consent was not obtained from the study participants as only de-identified data were obtained from the LHIRD 2010 , and a waiver of patient consent was provided by the ethics committee for this study.

\section{Consent for publication}

Not applicable.

\section{Competing interests}

The authors declare that they have no competing interests.

\section{Author details}

${ }^{1}$ Department of Pharmacy, China Medical University and China Medical University Beigang Hospital, Yunlin County, Taiwan, ROC. ${ }^{2}$ Department of Medical Research, Chung Shan Medical University Hospital, Taichung, Taiwan, ROC. ${ }^{3}$ Division of Cardiology, Department of Internal Medicine, Chung Shan Medical University Hospital and Chung Shan Medical University, Taichung, Taiwan, ROC.

Received: 18 December 2019 Accepted: 31 May 2020

Published online: 05 June 2020 


\section{References}

1. NCD Risk Factor Collaboration. Worldwide trends in diabetes since 1980 a pooled analysis of 751 population-based studies with 4.4 million participants. Lancet. 2016;387(10027):1513-30.

2. Neuen BL, Cherney DZ, Jardine MJ, Perkovic V. Sodium-glucose cotransporter inhibitors in type 2 diabetes: thinking beyond glucose lowering. CMAJ. 2019:191(41):E1128-35.

3. Lin Y, Li H, Lan X, Chen X, Zhang A, Li Z. Mechanism of and therapeutic strategy for atrial fibrillation associated with diabetes mellitus. Sci World J. 2013;2013:209428.

4. Bell DSH, Goncalves E. Atrial fibrillation and type 2 diabetes: Prevalence, etiology, pathophysiology and effect of anti-diabetic therapies. Diabetes Obes Metab. 2019;21(2):210-7.

5. Balkau $B$, Jouven $X$, Ducimetière $P$, Eschwège $E$. Diabetes as a risk factor for sudden death. Lancet. 1999;354(9194):1968-9.

6. Weidner K, Behnes M, Schupp T, Rusnak J, Reiser L, Bollow A, Taton G, Reichelt T, Ellguth D, Engelke N, Hoppner J, El-Battrawy I, Mashayekhi K, Weiß C, Borggrefe M, Akin I. Type 2 diabetes is independently associated with all-cause mortality secondary to ventricular tachyarrhythmias. Cardiovasc Diabetol. 2018:17(1):125.

7. Chen-Scarabelli C, Scarabelli TM. Electrophysiology, Suboptimal glycemic control, independently of QT interval duration, is associated with increased risk of ventricular arrhythmias in a high-risk population. Pacing Clin Electrophysiol. 2006;29(1):9-14.

8. Zinman B, Wanner C, Lachin JM, Fitchett D, Bluhmki E, Hantel S, Mattheus M, Devins T, Johansen OE, Woerle HJ, Broedl UC, Inzucchi SE, EMPA-REG OUTCOME Investigators. Empagliflozin, cardiovascular outcomes, and mortality in type 2 diabetes. N Engl J Med. 2015;373(22):2117-28.

9. Rådholm K, Figtree G, Perkovic V, Solomon SD, Mahaffey KW, de Zeeuw D, Fulcher G, Barrett TD, Shaw W, Desai M, Matthews DR, Neal B. Canagliflozin and heart failure in type 2 diabetes mellitus: results from the CANVAS Program. Circulation. 2018;138(5):458-68.

10. Clegg LE, Penland RC, Bachina S, Boulton DW, Thuresson M, Heerspink HJL, Gustavson S, Sjöström CD, Ruggles JA, Hernandez AF, Buse JB, Mentz RJ, Holman RR. Effects of exenatide and open-label SGLT2 inhibitor treatment, given in parallel or sequentially, on mortality and cardiovascular and renal outcomes in type 2 diabetes: insights from the EXSCEL trial. Cardiovasc Diabetol. 2019;18(1):138.

11. Shao SC, Chang KC, Hung MJ, Yang NI, Chan YY, Chen HY, Kao Yang YH, Lai EC. Comparative risk evaluation for cardiovascular events associated with dapagliflozin vs. empagliflozin in real-world type 2 diabetes patients: a multi-institutional cohort study. Cardiovasc Diabetol. 2019;18(1):120.

12. Matthews VB, Elliot RH, Rudnicka C, Hricova J, Herat L, Schlaich MP. Role of the sympathetic nervous system in regulation of the sodium glucose cotransporter 2. J Hypertens. 2017;35(10):2059-68.

13. Wan N, Rahman A, Hitomi H, Nishiyama A. The effects of sodium-glucose cotransporter 2 inhibitors on sympathetic nervous activity. Front Endocrinol (Lausanne). 2018;9:421.

14. Sano M. Hemodynamic effects of sodium-glucose cotransporter 2 inhibitors. J Clin Med Res. 2017;9(6):457-60.

15. Verma S, McMurray JJV. SGLT2 inhibitors and mechanisms of cardiovascular benefit: a state-of-the-art review. Diabetologia. 2018;61(10):2108-17.

16. Durak A, Olgar Y, Degirmenci S, Akkus E, Tuncay E, Turan B. A SGLT2 inhibitor dapagliflozin suppresses prolonged ventricular-repolarization through augmentation of mitochondrial function in insulin-resistant metabolic syndrome rats. Cardiovasc Diabetol. 2018;17(1):144.

17. Austin PC. The use of propensity score methods with survival or timetoevent outcomes: reporting measures of effect similar to those used in randomized experiments. Stat Med. 2014;33(7):1242-58.

18. Ferrannini E, Solini A. SGLT2 inhibition in diabetes mellitus: rationale and clinical prospects. Nat Rev Endocrinol. 2012;8(8):495-502.

19. DeFronzo RA, Davidson JA, Del Prato $S$. The role of the kidneys in glucose homeostasis: a new path towards normalizing glycaemia. Diabetes Obes Metab. 2012:14(1):5-14
20. Zheng SL, Roddick AJ, Aghar-Jaffar R, Shun-Shin MJ, Francis D, Oliver N, Meeran K. Association between use of sodium-glucose cotransporter 2 inhibitors, glucagon-like peptide 1 agonists, and dipeptidyl peptidase 4 inhibitors with all-cause mortality in patients with type 2 diabetes: a systematic review and meta-analysis. JAMA. 2018;319(15):1580-91.

21. Wiviott SD, Raz I, Bonaca MP, Mosenzon O, Kato ET, Cahn A, Silverman MG Zelniker TA, Kuder JF, Murphy SA, Bhatt DL, Leiter LA, for the DECLARETIMI 58 Investigators, et al. Dapagliflozin and cardiovascular outcomes in type 2 diabetes. N Engl J Med. 2019;380:347-57.

22. McMurray JJV, Solomon SD, Inzucchi SE, Køber L, Kosiborod MN, Martinez FA, Ponikowski P, Sabatine MS, Anand IS, Bělohlávek J, Böhm M, Chiang CE, for the DAPA-HF Trial Committees and Investigators, et al. Dapagliflozin in patients with heart failure and reduced ejection fraction. N Engl J Med. 2019:381:1995-2008.

23. Kosiborod M, Cavender MA, Fu AZ, Wilding JP, Khunti K, Holl RW, Norhammar A, Birkeland Kl, Jørgensen ME, Thuresson M, Arya N, Bodegård J, Hammar N, Fenici P, CVD-REAL Investigators and Study Group. Lower risk of heart failure and death in patients initiated on sodium-glucose cotransporter-2 inhibitors versus other glucose-lowering drugs: the CVD-REAL study (comparative effectiveness of cardiovascular outcomes in new users of sodium-glucose cotransporter-2 inhibitors). Circulation. 2017;136(3):249-59.

24. Böhm M, Slawik J, Brueckmann M, Mattheus M, George JT, Ofstad AP, Inzucchi SE, Fitchett D, Anker SD, Marx N, Wanner C, Zinman B, Verma S. Efficacy of empagliflozin on heart failure and renal outcomes in patients with atrial fibrillation: data from the EMPA-REG OUTCOME trial. Eur J Heart Fail. 2020:22(1):126-35.

25. Kim YG, Han SJ, Kim DJ, Lee KW, Kim HJ. Association between sodium glucose co-transporter 2 inhibitors and a reduced risk of heart failure in patients with type 2 diabetes mellitus: a real-world nationwide population-based cohort study. Cardiovasc Diabetol. 2018;17(1):91.

26. Stevenson WG, Ellison KE, Sweeney MO, Epstein LM, Maisel WH. Management of arrhythmias in heart failure. Cardiol Rev. 2002;10(1):8-14.

27. Kluger AY, Tecson KM, Lee AY, Lerma EV, Rangaswami J, Lepor NE, Cobble ME, McCullough PA. Class effects of SGLT2 inhibitors on cardiorenal outcomes. Cardiovasc Diabetol. 2019:18(1):99.

28. Zelniker TA, Bonaca MP, Furtado R, Mosenzon O, Kuder JF, Murphy SA, Bhatt DL, Leiter LA, McGuire DK, Wilding JPH, Budaj A, Kiss RG, Padilla F, Gause-Nilsson I, Langkilde AM, Raz I, Sabatine MS, Wiviott SD. Effect of dapagliflozin on atrial fibrillation in patients with type 2 Diabetes Mellitus: insights from the DECLARE-TIMI 58 trial. Circulation. 2020;141:1227-34.

29. Liou YS, Yang FY, Chen HY, Jong GP. Antihyperglycemic Drugs use and new-onset atrial fibrillation: a population-based nested case control study. PLoS ONE. 2018;13(8):e0197245.

30. Chen HY, Yang FY, Jong GP, Liou YS. Antihyperglycemic drugs use and new-onset atrial fibrillation in elderly patients. Euro J Clin Invest. 2017:47(5):388-93.

31. Chang SH, Wu LS, Chiou MJ, Liu JR, Yu KH, Kuo CF, Wen MS, Chen WJ, Yeh YH, See LC. Association of metformin with lower atrial fibrillation risk among patients with type 2 diabetes mellitus: a population-based dynamic cohort and in vitro studies. Cardiovasc Diabetol. 2014;13(1):123.

32. Chang $\mathrm{CY}$, Yeh YH, Chan YH, Liu JR, Chan YH, Chang SH, Lee HF, Wu LS, Yen KC, Kuo CT, See LC. Dipeptidyl peptidase-4 inhibitor decreases the risk of atrial fibrillation in patientswith type 2 diabetes: a nationwide cohort study in Taiwan. Cardiovasc Diabetol. 2017;16(7):156.

\section{Publisher's Note}

Springer Nature remains neutral with regard to jurisdictional claims in published maps and institutional affiliations. 